\title{
PATTERN OF VALVULAR LESIONS IN RHEUMATIC HEART DISEASE IN A TERTIARY CARE INSTITUTE, TAMILNADU
}

Perumal Jaisankar1, Gopalakrishnan Senthilkumar ${ }^{2}$

${ }^{1}$ Senior Assistant Professor, Department of Cardiology, Thanjavur Medical College, Thanjavur.

${ }^{2}$ Professor and HOD, Department of Cardiology, Thanjavur Medical College, Thanjavur.

ABSTRACT
BACKGROUND
Rheumatic heart disease (RHD) is a major contributor to morbidity and premature death in poor and developing countries like
India. RHD predominantly affects young and working age group.
Objective- To evaluate relative frequency of the various cardiac valvular lesions in Rheumatic heart disease (RHD) in patients who
underwent Echocardiogram in the Department of Cardiology, Thanjavur Medical College, Thanjavur, Tamilnadu.

\section{MATERIALS AND METHODS}

This retrospective descriptive study was conducted at Cardiology Department based on transthoracic two dimensional echocardiogram reports, diagnosed as RHD (Rheumatic heart disease) from January 2016 to December 2016. The reports were retrieved from computerised database and demographic features like age, sex, type of valvular lesion were analysed.

\section{RESULTS}

Out of 17,625 patients who underwent echocardiogram in the Department of Cardiology, 428 patients (2.4 \%) were diagnosed with rheumatic heart disease. The commonly affected age group was 21 to 40 years. The distribution being 120 males (28\%), 288 females (67.2\%) and 20 children (4.6\%). Mitral Regurgitation was the predominant valvular lesion affecting 328 (76.6\%) patients with female preponderance of $239(72.8 \%)$ patients. The second most common valvular lesion was Mitral Stenosis. It was diagnosed in 287 patients constituting $67.05 \%$. The incidence was most common in females (205 cases, 71\%) when compared to males (82 cases 29\%). Of those 287 patients, 139 (48.4\%) patients had severe MS and 92 (32.0\%) had moderate MS. Aortic Regurgitation (AR) was present in 126 (29.4\%) patients and almost always (99\%) in combination. Mixed valvular lesions (MS with MR) were present in 117 (27.3\%) of patients. The least common lesion was Aortic stenosis (AS) noted in 24 (5.6\%) patients. Out of 118 patients with multivalvular lesions, MS with MR with AR were found in 65 (55.08\%) patients.

\section{CONCLUSION}

The most common valvular lesion reported in our study was multivalvular lesion. The predominant pure lesion was Mitral regurgitation followed by Mitral stenosis, Aortic regurgitation and MS with MR.

\section{KEYWORDS}

Rheumatic Heart Disease, Mitral Regurgitation, Mitral Stenosis, Aortic Regurgitation, Aortic Stenosis.

HOW TO CITE THIS ARTICLE: Jaisankar P, Senthilkumar G. Pattern of valvular lesions in rheumatic heart disease in a tertiary care institute, Tamilnadu. J. Evolution Med. Dent. Sci. 2017;6(50):3813-3817, DOI: 10.14260/Jemds/2017/824

\section{BACKGROUND}

The most common cause of valvular heart disease in the world is Rheumatic heart disease (RHD).[1] About 15.6 million people are affected by RHD worldwide. Approximately, 4,70,000 new cases are diagnosed and 2,33,000 deaths have been attributed to RHD. ${ }^{[2]}$ Although the incidence of RHD has declined in the industrialised countries, RHD still constitutes a major health problem in developing countries due to its high prevalence.

Acute Rheumatic Fever (ARF) occurs as delayed sequelae to pharyngitis with Group A Beta-haemolytic Streptococci (GABHS).

Financial or Other, Competing Interest: None.

Submission 17-05-2017, Peer Review 09-06-2017,

Acceptance 16-06-2017, Published 22-06-2017.

Corresponding Author:

Perumal Jaisankar,

F-16, Royal Denizen,

Pattabiraman Street,

Tennur, Trichy-620017.

E-mail: jaicardio@gmail.com

DOI: $10.14260 /$ jemds $/ 2017 / 824$
It is an abnormal autoimmune response due to molecular mimicry between the M Protein on GABHS cell wall and cardiac myosin. [3] Rheumatic fever, the precursor to RHD leads to irreversible valve damage and heart failure.[4] Environmental factors such as poverty, overcrowding, malnutrition, genetic susceptibility related to human leukocyte antigen (HLA) alleles, virulent strains of GABHS all contribute to ARF and subsequently RHD. [5]

A high prevalence of ARF and RHD has been reported in south East Asia, Western pacific and Africa.[6] Due to ineffective health resources and lack of awareness of the disease, inappropriate primary prevention with timely antibiotic treatment of pharyngitis and secondary prophylaxis after ARF, the incidence is high in developing countries when compared to developed countries.

The present study is designed to investigate the patterns of left-sided valvular involvement in patients with Rheumatic heart disease as assessed by echocardiography done at Cardiology Department of a tertiary care referral hospital, Southern India. 


\section{MATERIALS AND METHODS}

Thanjavur Medical College and Hospital is a tertiary referral centre with 1176 beds catering to the needs of 69,000 patients per year. This retrospective descriptive study was conducted in patients diagnosed as having RHD based on Echocardiographic examination during the period January 2016 to December 2016. The data collected includes age, sex, clinical diagnosis and findings on Transthoracic Echocardiography. All the patients underwent a standard two dimensional, colour Doppler and M-mode echocardiography. Echocardiography was performed in accordance with American College of Cardiology/American Heart Association guidelines by consultant cardiologists using PHILIPS HD 11XE and ALOKA SSD4000 ultrasound system. Only the firsttime Echocardiogram of each patient was included for the study to avoid repetition bias. Statistical analysis was performed with SPSS 16.

The patients were divided into Ischaemic Heart Disease (IHD), Rheumatic Heart Disease (RHD), Congenital Heart Disease (CHD) and Cardiomyopathies. All those patients who had rheumatic heart disease were included in this study. Remaining lesions other than RHD were excluded.

Mitral stenosis was diagnosed on the presence of valve thickening, diastolic doming, restriction of leaflet motions and was quantified by pressure half-time and planimetry. Presence of features like calcification, fibrosis, limited leaflet excursion and fusion of commissures and chordae tendineae were also identified. Mitral regurgitation was diagnosed by the presence of thickened valves, dilated mitral valve annuli, and left atrial and left ventricular dilatation, and lack of coaptation of the mitral valve leaflets in systole. Doppler echocardiographic analyses identified the presence and severity of regurgitation of the aortic, mitral and tricuspid valves. Thickened and calcified aortic valve leaflets with reduced leaflet motion (Aortic cusp separation less than 9 $\mathrm{mm}$ ) suggested aortic stenosis along with a peak gradient of more than $20 \mathrm{mmHg}$ in continuous-wave Doppler. Aortic regurgitation was diagnosed when echocardiography with Doppler interrogation of the aortic valve showed the spatial extent of the colour Doppler aliasing in the outflow tract and was used as a rough guide of the severity of aortic insufficiency. Echocardiographic findings associated with pulmonary hypertension included a dilated pulmonary artery and dilation and hypertrophy of the Right Ventricle (RV), diastolic flattening of the interventricular septum, and Doppler evidence of pulmonary hypertension.

\section{RESULTS}

About 17,625 patients underwent echocardiography during our study period, out of which $428(2.4 \%)$ patients were diagnosed as RHD. Out of 428 patients, 120 (28\%) were male and $288(67 \%)$ were female and $20(5 \%)$ were in the paediatric age group. The female to male ratio was 2.2:1. Around $50 \%$ of female cases were in the age group of $21-40$ years. The number of male patients were equally distributed in the age group of 21-40 and 40-60 years [Fig. I].

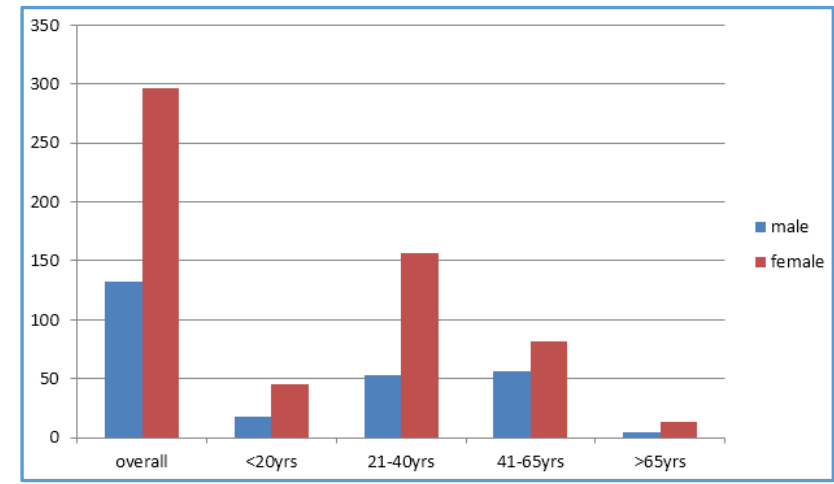

Figure I. Distribution of Age and Sex among Patients Presenting with RHD.

\begin{tabular}{|c|c|c|}
\hline Valvular Lesion & $\begin{array}{c}\text { No. of } \\
\text { patients }\end{array}$ & \% of Total \\
\hline Pure Mitral Stenosis & 77 & $17.99 \%$ \\
\hline $\begin{array}{c}\text { Pure Mitral } \\
\text { Regurgitation }\end{array}$ & 101 & $23.59 \%$ \\
\hline Aortic Stenosis & 3 & $0.7 \%$ \\
\hline Aortic Regurgitation & 12 & $2.8 \%$ \\
\hline MS with MR & 117 & $27.33 \%$ \\
\hline Multivalvular & 118 & $27.57 \%$ \\
\hline Table I. Shows the Distribution of Pure and Mixed Valvular \\
Lesion in RHD \\
\hline
\end{tabular}

The most common valvular lesion reported in our study was multivalvular lesion constituting 118 cases (27.51\%). Among pure lesions, MR was the commonest with 101 cases (23.59\%) when compared to pure mitral stenosis with 77 cases $(17.99 \%)$ (Table I). The least common lesion was aortic stenosis ( 3 cases, $0.7 \%$ ).

\begin{tabular}{|c|c|c|c|}
\hline Valvular Lesion & Pure & Mixed & Total \\
\hline Mitral Stenosis & 77 & 209 & 286 \\
\hline Mitral Regurgitation & 101 & 120 & 221 \\
\hline Aortic Stenosis & 3 & 21 & 24 \\
\hline Aortic Regurgitation & 12 & 114 & 126 \\
\hline \multicolumn{4}{|c|}{ Table II } \\
\hline
\end{tabular}

Among the mixed lesions, MS predominates with 209 cases followed by MR with 101 cases (Table II). MS with MR was the most common presentation seen in 117 cases (27.53\%) [Fig. II].

\section{PERCENTAGE OF VALVULAR LESIONS IN RHD}

$\because \mathrm{MS}=\mathrm{MR} \| \mathrm{AS} \backsim \mathrm{AR} \backsim \mathrm{MS}, \mathrm{MR}=\mathrm{MS}, \mathrm{MR}, \mathrm{AR}$

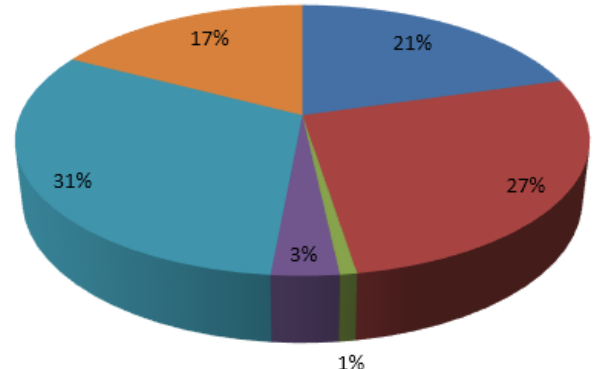

$1 \%$

Figure II. Percentage of Valvular Lesions in RHD 
Table III shows distribution of multivalvular lesion. MS with MR with AR was the commonest combination seen in 65 patients $(27.65 \%)$ followed by MR with AR 23 patients (9.74\%). The least common combination was MS with AS seen in 2 patients.

\begin{tabular}{|c|c|c|}
\hline $\begin{array}{c}\text { Contribution of } \\
\text { Valvular Lesion }\end{array}$ & Frequency & \% \\
\hline MS + MR + AR & 65 & 27.65 \\
\hline MR + AR & 23 & 9.7 \\
\hline MS + AR & 9 & 3.8 \\
\hline MS + MR + AS + AR & 9 & 3.8 \\
\hline MS + MR & 117 & 49.78 \\
\hline Others & 12 & 5.1 \\
\hline \multicolumn{3}{|c|}{ Table III }
\end{tabular}

Mitral Regurgitation was seen in 328 (76.6\%) patients with female preponderance of 239 cases (72.8\%). The number of male patients reported with MR were 89 cases (27.13\%). 15 patients (4.5\%) had severe mitral regurgitation.

In individual lesion, mitral stenosis was diagnosed in 287 patients $(67.05 \%)$ with female to male ratio $2.5: 1$. Of these 139 (48.4\%) patients had severe MS, while $92(32 \%)$ and 56 (19.5\%) patients had moderate MS and mild MS respectively.

Aortic regurgitation is the common aortic valvular lesion seen in rheumatic heart disease. In our study, 126 (29.43\%) patients had AR with female preponderance of 83 cases $(16.5 \%)$. Only $43(34.12 \%)$ male patients were diagnosed with AR.

The incidence of pulmonary hypertension amounted to $11.21 \%$ in our cohort. More than two-third (68.75\%) of patients were female. The most common lesion associated with pulmonary hypertension was mitral stenosis [40 cases, (83.33\%)]. Among patients with pulmonary hypertension, $50 \%$ (24 cases) had severe pulmonary hypertension.

In our cohort, 24 cases (5.6\%) had left ventricular systolic dysfunction. Females (66.66\%) were more commonly affected by LV systolic dysfunction when compared to male (33.33\%). Multivalvular lesion was the commonest lesion associated with left ventricular systolic dysfunction [7 cases, $30 \%]$.

Being a tertiary care hospital, significant proportion of patients were post-operative and post procedure patients. A total of $64(14.75 \%)$ such cases were registered. Out of these, 38 cases $(8.8 \%)$ were post procedure and 26 cases $(6.07 \%)$ were valve replacement cases. [Table IV]. Infective endocarditis is one of the complications of rheumatic valvular heart disease. In our study, 5 cases $(1.1 \%)$ of infective endocarditis have been reported. Left atrial clot is also one of the complication of rheumatic heart disease almost always seen in mitral stenosis. 7 cases $(1.6 \%)$ of left atrial clot have been reported in our study.

\begin{tabular}{|c|c|c|}
\hline Procedure/ Surgery & No. of Cases & \% of Total RHD \\
\hline $\begin{array}{c}\text { Mitral Valve } \\
\text { Replacement }\end{array}$ & 24 & $5.6 \%$ \\
\hline $\begin{array}{c}\text { Double Valve } \\
\text { Replacement }\end{array}$ & 1 & $0.2 \%$ \\
\hline $\begin{array}{c}\text { Aortic Valve } \\
\text { Replacement }\end{array}$ & 1 & $0.2 \%$ \\
\hline CMC + BMV & 38 & $8.7 \%$ \\
\hline Total & $\mathbf{6 4}$ & $\mathbf{1 4 . 7 5 \%}$ \\
\hline \multicolumn{3}{|c|}{ Table IV } \\
\hline
\end{tabular}

\section{DISCUSSION}

Rheumatic heart disease is now rare in western countries, but still it is a major public health problem in developing countries like India. Nowadays there has been a decline in prevalence of RHD in India when compared to 80s and 90s. The incidence of RHD in our study is $2.4 \%$ which is lower when compared to previous studies by Amajel Abrenet et al $(5.7 \%)^{[7]}$ and Ramchandra Kafle et al (4.84\%).[8] The prevalence rates of RHD have been found to be $1.3-4.5 /$ 1000 population common in children in $5-15$ age group. ${ }^{[7,8]}$ In our study, RHD was common in younger age group (21-40) years. This is in concordance with Sharma et al[8] and Mohammed Fahem et al[9] This is attributed to prevalence of group A streptococcal infection and consequently, Rheumatic fever is more common in school children. In our study, females were more commonly affected than men. This is in concordance with study done by Nikesh, Raj Shrestha at al, Mohammed Fahem Rajeen Bhardway et al.[9] It has been hypothesised that female predominance is due to greater exposure to GABHS because of greater involvement of women in child bearing age group, increased innate susceptibility, or reduced medical access to medical care and no scientific reason for female predominance of the disease has been explained.[10]

The female to male ratio in our study is $2.2: 1$ and was consistent with previous studies observing a higher prevalence of RHD in women. In our study, predominantly the patients had multi valvular lesions $(27.57 \%)$ and mixed valvular lesions $(27.33 \%)$ indicating that they were identified only in the advanced stage of the disease. This may be due to lack of proper primary health care facilities and missing an early Rheumatic Fever symptoms by a physician. Due to poverty, illiteracy, lack of awareness and poor health facilities many of our patients defer primary prophylaxis for Rheumatic fever. Poor Compliance with long term painful injections of benzathine penicillin forces the patients to withhold secondary prophylaxis of Rheumatic heart disease. Finally delay in timely surgery due to high expenses, lack of education and sometimes due to patients reluctance results in end stage Rheumatic heart disease.

When considering individual valves in our study, mitral valve is the most commonly affected valve which coincides with the finding of other studies[11,12,13] and mitral regurgitation was the predominant lesion. But study done by Rabimall et al[14] and others showed MS as the common valvular lesions. The least common lesion is Aortic stenosis similar to other studies. We found AS to be more common in male similar to the study by Huma Jain et al.[15] Aortic regurgitation is more common in female in contrary to the study by Shrestha et al.[16] In our study, mitral regurgitation was the dominant valvular lesion. The cause being uncertain. The peak incidence of MR and AR was in the age group of 15 to 30 years while MS was observed in middle aged persons from 30 to 49 years. The above findings are consistent with Sani U, Karaye KM et al.[10] Mitral stenosis was frequently seen in women (71\%) when compared to men $(29 \%)$ coinciding with Mohammad MR study.[17]

Management of advanced RHD by surgery in the form of valvuloplasty or valve replacement has limited options in developing county like ours. Surgical and interventional procedures are essential to reduce mortality and morbidity in RHD. Balloon mitral valvotomy, closed commissurotomy and 
valve replacement are done in patients with valvular heart disease.[18] In our study. $6.07 \%$ of patients had valve replacement and $8.8 \%$ of patients had valvuloplasty and commissurotomy.

The left-sided rheumatic valvular pathology, over a period, results in pulmonary venous hypertension followed by pulmonary arterial hypertension. Compared to patients with primary forms of PHT, those secondary to valvular heart disease (VHD) have significantly elevated pulmonary artery pressure (PAP) and pulmonary vascular resistance, but lesser cardiac output.[19] Echocardiography is used to confirm the diagnosis, which may show dilated right ventricle. Doppler interrogation of tricuspid valve regurgitation (TR) and/or pulmonary regurgitation (PR) can be used to quantify the elevated PAP. Pulmonary artery systolic pressure lesser than $30 \mathrm{mmHg}$ is defined as mild and greater than $50 \mathrm{mmHg}$ as severe PHT.[19] Prevalence of pulmonary hypertension in Rheumatic heart disease in India is $1.5-2 / 1000$ cases,[20] which similar to our cohort with 1.2-2.1/1000 cases. Pulmonary Hypertension, a frequent complication of rheumatic mitral valve disease is known to be associated with both Rheumatic MS and MR. In our study, pulmonary hypertension was the most common complication associated with MS which is in concordance with study by Harikrishnan et al.[20] PHT influences the natural history of the disease, affects the response to treatment and also the postintervention prognosis.

Left ventricular systolic dysfunction is not a common feature primarily due to Rheumatic heart disease. LV dysfunction is very rare in Mitral Stenosis and late feature in other lesions like Mitral regurgitation, Aortic regurgitation and Aortic stenosis. Proposed mechanisms of LV dysfunction in Mitral stenosis are restriction or tethering of myocardium by the scarred mitral apparatus and abnormal interventricular septal motion related to RV volume overload. Progressive remodelling with increased wall stress due to dilatation can ultimately lead to irreversible damage to myocardium, resulting in development of $\mathrm{LV}$ contractile dysfunction in patients with regurgitant lesions in RHD. In our study, Multivalvular lesion was the commonest lesion associated with systolic dysfunction.[21]

One of the common cause for young stroke in RHD is Left Atrial clot. ${ }^{[22]}$ In our study, $1.6 \%$ of patients had left atrial clot. Early detection of atrial fibrillation and left atrial clot and subsequent treatment with anti-coagulation helps in prevention of young stroke. Infective endocarditis was reported in $1.1 \%$ of cases in our study. Hence, early recognition of RHD and infective endocarditis prophylaxis will prevent the complications of RHD.

Our observational study had several limitations. Our analytical study reflects a single centre, hospital-based retrospective observation. Moreover, the symptomatic status, clinical details, other investigations and clinical outcome/followup information were not available for all the patients. This study reflects the prevalence of valvular lesion in selected patient population, hence the results are not applicable to the general population because of referral bias.

\section{CONCLUSION}

Rheumatic Heart disease is still the common heart disease affecting population in active and productive life. Females were more commonly affected then males with female to male ratio of 2.2: 1 seen predominantly in the age group of 21-40 years. Mitral regurgitation was the commonest pure valvular lesion. Among multivalvular lesions, mitral regurgitation, mitral stenosis and aortic regurgitation was the commonest combination. Post-operative followup patients contribute significant proportion with equal distribution in valve replacement and commissurotomy. Being a tertiary care hospital we have to give care not only for rheumatic valvular heart patients but also to postoperative followup cases.

\section{REFERENCES}

[1] Carapetis JR, McDonald M, Wilson NJ. Acute Rheumatic fever. Lancet 2005;366(9480):155-68.

[2] Rheumatic fever and rheumatic heart disease. Report of WHO study group. Technical report. Series NO.764, Geneva: WHO, 1998.

[3] Guilherme L, Khalil J. Rheumatic fever: from sore throat to autoimmune heart lesions. Int Arch Allergy Immune 2004;134(1):56-64.

[4] Marijon E, Mirabel M, Celermajer DS, et al. Rheumatic heart disease. Lancet 2012;379(9819):953-64.

[5] Kaplan EL, Johnson DR, Cleary PP, et al. Group A streptococcal serotypes isolated from patients and sibling contacts during the resurgence of rheumatic fever in the United States in the 1980s. J Infect Dis 1989;159(1):101-3.

[6] Seckeler MD, Hoke TR. The worldwide epidemiology of acute rheumatic fever and rheumatic heart disease. Clin Epidermiol 2011;3(1):67-87.

[7] Abrar A, Khan S, Rehman M, et al. Frequency of rheumatic heart disease in patients undergoing Echocardiography in District Dera Ismail khan. Gomal J Med Sci 2014;12(3):147-50.

[8] Sharma M, Saxena A, Kothari SS, et al. Acute rheumatic fever in children: experience from a cardiac center. Indian Heart J 1999;51:652-3.

[9] Faheem M, Hafizullah M, Gul A, et al. Pattern of valvular lesions in rheumatic heart disease. JPMI 2007;21(2):99-103.

[10] Sani MU, Karaye KM, Borodo MM. Prevalence and pattern of rheumatic heart disease in the Nigerian savannah: an echocardiographic study. Cardiovasc J Afr 2007;18(5):295-9.

[11] Dajani AS. Rheumatic fever. In: Braunwald E, Ziper DP, Libby P. eds. Heart disease, a textbook of cardiovascular medicine. $6^{\text {th }}$ edn. Philadelphia: WB Saunders 2001:2192.

[12] Danbauchi SS, Alhassan MA, David So, et al. Spectrum of rheumatic heart disease in Zaria, Northern Nigeria. Ann Afr Med 2004;3(1):17-21.

[13] Khan MH, Tasneem H, Khan SZ, et al. Echocardiogram: Screening for valvular heart disease in an Out-patient clinic. Med Today 2005;3(3):133-6.

[14] Malla R, Thapaliya S, Gurung P, et al. Patterns of valvular involvement in rheumatic heart disease patients taking Benzathine Penicillin at Shahid Gangalal National Heart Centre, Kathmandu, Nepal. Nepalese Heart Journal 2016;13(2):25-7. 
[15] Humagain S, Gurung R, Pant P, et al. Pattern of valvular involvement and demographic features of patients on injection Benzathine Penicillin at Dhulikhel Hospital. Nepalese Heart Journal 2012;9(1):16-9.

[16] Shrestha NR, Pilgrim T, Karki P, et al. Rheumatic heart disease revisited: patterns of valvular involvement from a consecutive cohort in eastern Nepal. J Cardiovasc Med (Hagerstown) 2012;13(11):755-9.

[17] Movahed MR, Ahmadi-Kashani M, Kasravi B, et al. Increased prevalence of mitral stenosis in women. J Am Soc Echocardiogr 2006;19(7):911-3.

[18] Kafle RC Alurkar VM, Paudel N, et al. Pattern of valvular involvement in rheumatic heart disease patients in a tertiary care hospital of Western Nepal. Nepalese Heart Journal 2016;13(2):29-31.
[19] Kabbani SS, Bashour T, Dunlap R, et al. Mitral stenosis with severe pulmonary hypertension. Tex Heart Inst J 1982;9(3):307-10.

[20] Harikrishnan S, Sanjay G, Ashishkumar M, et al. Pulmonary hypertension registry of Kerala (PROKERALA) - rationale, design and methods. Indian Heart J 2016;68(5):709-15.

[21] Mohan JC, Mohan V. Subclinical left ventricular systolic dysfunction in chronic mitral regurgitation and its potential impact on management: quo vadis? Indian Heart J 2012;64(3):249-53.

[22] Lakshminarayan K, Solid CA, Collins AJ, et al. Atrial fibrillation and stroke in general medicare population. A 10 year perspective (1992-2002). Stroke 2006;37(8):1969-74. 